\title{
PENGARUH ACHANGE, OSHIP, LEVERAGE, DAN RECEIVABLE TERHADAP FRAUD
}

\author{
Ratih Qadarti Anjilni \\ Fakultas Ekonomi, Universitas Pamulang \\ dosen02425@unpam.ac.id
}

\begin{abstract}
Financial statements are a means of financial information for internal and external parties in decision making. The information contained in the financial statements is very helpful for owners or other parties such as creditors and investors in assessing the company. When a public company publishes its financial statements, it wants to describe the situation and conditions in the best possible condition (Skousen et al., 2009). This study aims to test the influence of achange, oship, leverage and receivable on fraud. Consumer Goods Sector Manufacturing Companies listed on the Indonesia Stock Exchange as many as 39 companies in the period 2015 - 2019 are the population in this study. The samples in this study were 17 manufacturing companies in the Consumer Goods sector in the period 2015 - 2019 that allegedly committed Fraud. Detection of companies that commit Fraud using the Beneish M-Score method. Data Analysis uses a panel regression model with the Eviews 8.0 program. The results showed that only leverage has a significant negative effect on partial fraud. achange, oship and receivable have no significant effect on fraud, but achange, oship, leverage and receivable simultaneously have a significant positive effect on Fraud. This research is expected to help tax fission, companies and the public in detecting early fraud on financial statements that occur in the company.
\end{abstract}

Keywords: Achange; Oship; Leverage; Receivable; Fraud

\begin{abstract}
Abstrak
Laporan keuangan merupakan sarana informasi keuangan bagi pihak internal dan eksternal dalam pengambilan keputusan. Informasi yang terdapat dalam laporan keuangan sangat membantu pemilik atau pihak lain seperti kreditur dan investor dalam menilai perusahaan. Pada saat perusahaan publik menerbitkan laporan keuangannya, sesungguhnya perusahaan ingin menggambarkan situasi dan kondisinya dalam keadaan terbaik (Skousen et al., 2009). Penelitian ini bertujuan untuk menguji pengaruh Achange, Oship, Leverage dan receivable terhadap Fraud. Perusahaan Manufaktur Sektor Barang Konsumsi yang terdaftar di Bursa
\end{abstract}


Efek Indonesia sebanyak 39 perusahaan periode 2015 -2019 merupakan populasi pada penelitian ini. Sampel dalam penelitian ini adalah 17 perusahaan manufaktur sektor Barang Konsumsi Periode 2015 - 2019 yang diduga melakukan Fraud. Pendeteksian perusahaan yang melakukan Fraud menggunakan metode Beneish $M$-Score. Data Analisis menggunakan model regresi panel dengan program Eviews 8.0. Hasil penelitian menunjukkan bahwa hanya leverage yang berpengaruh signifikan negatif terhadap fraud secara parsial. Achange, oship dan receivable tidak berpengaruh signifikan terhadap fraud, tetapi achange, oship, leverage dan receivable secara simultan berpengaruh signifikan positif terhadap fraud. Penelitian ini diharapkan dapat membantu fiskus pajak, perusahaan dan masyarakat dalam mendeteksi lebih dini kecurangan atas laporan keuangan yang terjadi di perusahaan.

Kata kunci: Achange; Oship; Leverage; Receivable; Fraud

\section{PENDAHULUAN}

Laporan keuangan merupakan sarana informasi keuangan bagi pihak internal dan eksternal dalam pengambilan keputusan. Informasi yang terdapat dalam laporan keuangan sangat membantu pemilik atau pihak lain seperti kreditur dan investor dalam menilai perusahaan. Pada saat perusahaan publik menerbitkan laporan keuangannya, sesungguhnya perusahaan ingin menggambarkan situasi dan kondisinya dalam keadaan terbaik (Skousen et al., 2009). Jensen dan Meckling (1976) menggambarkan hubungan antara pemegang saham atau dalam hal ini investor sebagai prinsipal dan manajer sebagai agen. Standar Profesional Akuntan Publik pada Pernyataan Standar Auditing (PSA) No. 70 (SA Seksi 316 paragraf 4) menjelaskan bahwa kecurangan sebagai salah saji atau penghilangan secara sengaja jumlah atau pengungkapan dalam laporan keuangan untuk mengelabuhi pemakai laporan keuangan. Dilansir dari BAPEPAM-LK dalam Elandi (2016), tabel berikut adalah perusahaan yang melantai di Bursa Efek Indonesia yang pernah terbukti melakukan kecurangan atau melakukan pengelabuan terhadap pemakai keuangan, baik kecurangan manipulasi pembukuan, insider trading maupun penggelapan pajak.

Tabel 1.1 Skandal Perusahaan go public di Indonesia

\begin{tabular}{ll}
\multicolumn{1}{c}{ Nama Perusahaan } & \multicolumn{1}{c}{ Tindakan Kecurangan } \\
\hline PT. Kimia Farma Tbk & Manipulasi Laporan Keuangan \\
PT. Indofarma Tbk & Manipulasi Laporan Keuangan \\
PT. Bank Lippo Tbk & Manipulasi Laporan Keuangan \\
PT. Asian Agri & Penggelapan Pajak \\
PT. Ades Alfindo Putrasetia Tbk & Insider Trading \\
PT. Perusahaan Gas Negara Tbk & Insider Trading \\
\hline
\end{tabular}

Sumber: Bapepam-LK, data diolah. dikutip dalam Elandi (2016)

* Corresponding author's e-mail:dosen02425@unpam.ac.id http://openjournal.unpam.ac.id/index.php/JABI 
Agar pendeteksian kecurangan laporan keuamgan mudah dilakukan, American Institute Certified Public Accountant (AICPA) menawarkan solusi dalam prosedur pendeteksian kecurangan dengan menerbitkan Statement of Auditing Standards (SAS). International Federation of Accountants (IFAC) sebuah organisasi Jerman yang membidangi standar-standar akuntansi, auditing dan kode etik pada tatanan global, juga menerbitkan International Standards on Auditing (ISA). Standar tersebut mengatur dan menggambarkan ilustrasi penyebab kecurangan, yaitu ISA no. 240 dan SAS no.99 yang didasarkan pada fraud triangle. Teori segitiga yang dicetuskan oleh D. R. Cressey (1953) ini mengkategorikan tiga kondisi penyebab perusahaan melakukan kecurangan, yaitu (1) pressure (2) opportunity (3) rationalization.

Menurut Turner et al. (2003), masukan dari ahli forensik dan akademisi menunjukkan bahwa evaluasi terhadap informasi tentang kecurangan akan meningkat ketika mempertimbangkan konteks fraud triangle. Kecurangan yang terjadi dapat disebabkan karena banyak hal, menurut Skousen, et al (2009) penyebab kecurangan banyak terjadi karena (1) Achange atau tuntutan agar kinerja perusahaan selalu terlihat baik (meskipun intern dan ekstern perusahaan dalam keadaan tidak stabil), (2) tekanan hutang berlebih dari pihak ketiga (Leverage), (3) adanya sifat opportunistic orang dalam perusahaan yang cendrung memanfaatkan kepemilikan sahamnya untuk mempengaruhi keadaan keuangan perusahaan (Oship), hingga (4) karakteristik industry (receivable) yang melibatkan estimasi-estimasi memiliki resiko salah saji dalam melaporkan laporan keuangannya. Praktek penyebab kecurangan tersebut pernah terjadi di Indonesia bahkan di dunia.

Praktik kecurangan yang terjadi pada perusahaan British Telecom di Italia, disebabkan karena leverage dan receivable. Tekanan pihak luar yang dalam hal ini hutang-hutang perusahaan banyak yang disembunyikan (tidak dilaporkan) oleh para chief, dilansir pada wartaekonomi.co.id pada 22 Juni 2017, “...dampak fraud akuntansi penggelembungan laba ini menyebabkan British Telecom harus menurunkan GBP530 juta dan memotong proyeksi arus kas selama tahun ini sebesar GBP500 juta untuk membayar utang -utang yang disembunyikan. Tentu saja British Telecom rugi membayar pajak penghasilan atas laba yang sebenarnya tak ada."

Tiffani (2015) mengungkapkan hanya variabel financial stability dengan menggunakan proksi achange, external pressure dengan proksi leverage yang berpengaruh signifikan terhadap kecurangan laporan keuangan." Selain itu Junita (2016) membuktikan bahwa Financial stability pressure yang diproksikan (achange), berpengaruh signifikan terhadap kecurangan laporan keuangan. Magfiroh, dkk (2015) juga membuktikan external pressure yang diproksikan dengan leverage berpengaruh. Namun, penelitian yang dilakukan oleh Elandi (2016) external pressure yang diproksikan dengan menggunakan proksi leverage ratio tidak berpengaruh terhadap financial statement fraud. 


\section{KERANGKA TEORITIS DAN PENGEMBANGAN HIPOTESIS}

Fraud is an action conducted by a single person or in a group that aims to take an advantage tends to harm others. There are three occasions that encourage Fraud, namely the drive that causes a person to do Fraud (pressure), opportunities that allow Fraud occurs (opportunity), and an important element in Fraud, namely perpetrators seek justification for their action (Nasution dalam Andriyanto, et all 2020).

Teori Fraud triangle adalah sebuah temuan keilmuan yang meneliti tentang faktor terjadinya kecurangan. Gagasan keilmuan ini pertama kali dikenalkan oleh Cressey (1953) dan dinamakan Fraud triangle. Fraud triangle theory berasal dari hipotesis atau dugaan Donald R. Cressey (1953). Gambaran penyebab kecurangan dari standar kecurangan (AICPA SAS No 99, ISA No 240, TSAS No 43), dan Institut Akuntan Indonesia (IAI) dalam Pernyataan SA No. 70 bersumberkan dari teori kecurangan yang dikenalkan oleh D. R. Cressey 1953 dalam Lou dan Wang (2009). Fraud triangle menjelaskan tiga faktor yang selalu ditemukan dalam setiap situasi FRAUD yaitu Pressure (Tekanan), Opportunity (Peluang) dan Rationalization (Rasionalisasi)

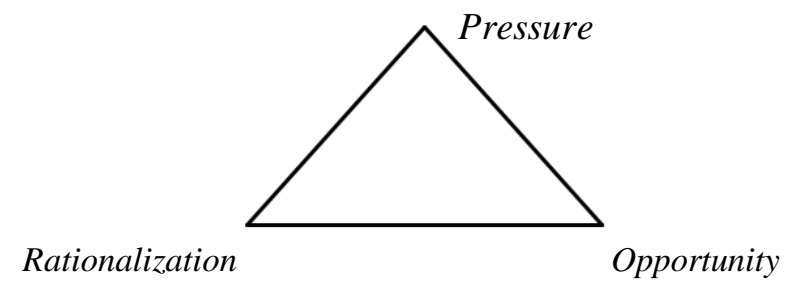

Sumber: FRAUD triangle theory oleh Cresey (1953)

\section{Gambar 2.1 Fraud Triangle}

Pressure adalah suatu tekanan kepada manusia untuk melakukan fraud (kecurangan). Tekanan yang dimaksud adalah tekanan terhadap gaya hidup, tuntutan ekonomi dan lain-lain. Termasuk hal keuangan dan maupun non keuangan. Dikutip dari laman SAS No. 99, terdapat empat jenis situas yang umum terjadi pada pressure yang dapat mengakibatkan kecurangan. Kondisi tersebut adalah external pressure, financial stability, personal financial need, dan financial targets.

Opportunity merupakan adanya kesempatan yang menjadi penyebab kecurangan pada laporan keuangan. pengendalian internal yang lemah, pengawasan manajemen yang kurang baik atau penyalahgunaan penggunaan posisi menjadi penyebab adanya opportunity. SAS No. 99 menyebutkan bahwa peluang pada kecurangan laporan keuangan dapat terjadi pada tiga kategori. Kondisi tersebut adalah receivable, ineffective monitoring, dan organizational structure.

Rasionalisasi menjadi salah satu faktor pemicu terjadinya fraud, di mana pelaku mencari pembenaran atas perbuatannya. Integritas manajemen adalah

* Corresponding author's e-mail:dosen02425@unpam.ac.id http://openjournal.unpam.ac.id/index.php/JABI 
penentu utama dari kualitas sebuah laporan keuangan. Ketika sebuah integritas manajemen dipertanyakan, maka keandalan dari suatu laporan keuangan diragukan. Perilaku tidak jujur dapat menjadi salah satu indikasi dalam kecurangan (Ramadhan dan Ruhiyat, 2020). Bagi mereka dengan standar moral yang lebih tinggi, mungkin tidak begitu mudah. Pelaku fraud selalu mencari pembenaran rasional untuk membenarkan perbuatannya.

Achange adalah persentase perubahan aset selama 2 tahun, achange yang digunakan untuk mengukur kondisi Financial stability. (Skousen et al, 2009) dan Tiffani (2015). Menurut Skousen et al. (2009), bentuk manipulasi laporan keuangan dilakukan oleh manajemen berkaitan dengan pertumbuhan aset perusahaan. Beasley (1998), COSO (1999), dan Dunn (2004) menunjukkan bahwa ketika para eksekutif memiliki sebuah saham keuangan yang signifikan di perusahaan, situasi keuangan pribadi mereka mungkin terancam oleh kinerja keuangan perusahaan (Skousen, et al, 2009). Oship sebagai proksi untuk mengukur personal financial need. Oship adalah ownership by insiders atau kepemilikan manajerial (Skousen et al, 2009).

Leverage adalah penggunaan aset dan sumber dana (source of funds) oleh perusahaan yang memiliki biaya tetap (beban tetap) dengan maksud agar meningkatkan keuntungan potensial pemegang saham. External pressure ini diproksikan menggunakan leverage (LEV) sesuai dengan penelitian sebelumnya yang dilakukan oleh Skousen et al. (2009), Tiffani (2015) dan Wulandari (2016). Jika leverage semakin tinggi, kemungkinan melakukan kecurangan serta pelanggaran perjanjian kredit semakin tinggi (Persons, 1999).

Receivable adalah persentase untuk mengukur pertumbuhan piutang perusahaan atas penjualan tiap tahun. Tingginya piutang dalam penjualan menurut penelitian. Skouses, et al (2009) menunjukan bahwa akun piutang merupakan aset yang memiliki risiko manipulasi lebih tinggi. Maka rawan terjadi kecurangan dalam laporan keuangan.

\section{Hubungan antara Achange dengan Fraud}

Loebbecke, Eining dan Wilingham (1989) dan Bell, Szykowny, dan Wilingham (1991) mengemukakan bahwa kasus di mana perusahaan memiliki pertumbuhan industri di bawah rata-rata, memungkinkan manajemen melakukan manipulasi laporan keuangan untuk meningkatkan prospek perusahaan (Skousen et al., 2009). Perusahaan berusaha meningkatkan prospek perusahaan yang baik salah satunya dengan merekayasa informasi kekayaan aset yang berkaitan dengan pertumbuhan aset yang dimiliki (Skousen et al., 2009). Oleh karena itu, rasio perubahan total aset dijadikan variabel. Berdasarkan uraian tersebut, diajukan hipotesis penelitian sebagai berikut:

$\mathrm{H}_{1}$ : Achange berpengaruh terhadap Fraud

\section{Hubungan antara Oship dengan Fraud}

Kepemilikan saham yang lebih besar dimiliki oleh orang dalam akan menyebabkan tugas setiap anggota dewan komisaris menjadi lebih khusus karena terdapat komite-komite yang lebih khusus dalam mengawasi perusahaan. 
Spesialisasi yang lebih besar tersebut dapat menunjukkan pengawasan yang lebih efektif. Sehingga semakin besar ukuran oship maka semakin besar kekuatan dari dewan komisaris dalam melakukan pengawasan sehingga kecenderungan para manajer atau direksi melakukan financial statement fraud akan lebih kecil.

Penelitian yang dilakukan Soraya (2013) oship berpengaruh positif signifikan terhadap financial statement fraud. Untuk itu, hipotesis untuk hubungan variabel oship dengan fraud adalah sebagai berikut:

$\mathrm{H}_{2}$ : oship berpengaruh terhadap fraud.

\section{Hubungan antara Leverage dengan Fraud}

Elandi (2016) mengatakan Leverage merupakan kemampuan untuk memenuhi pertukaran persyaratan pencatatan, membayar utang, atau memenuhi utang perjanjian diakui secara luas yang berasal dari pihak eksternal. Leverage dihitung menggunakan leverage ratio, yaitu rasio total utang dibagi dengan total aset (debt to assets ratio). Ketika perusahaan memiliki rasio leverage yang tinggi maka perusahaan itu memiliki utang yang besar. (Kasmir, 2013:152). Manajemen perusahaan akan merasa tertekan dengan utang yang semakin besar, karena risiko kreditnya juga akan tinggi, sehingga memungkinkan terjadinya kecurangan. Maka hipotesisnya sebagai berikut:

$\mathrm{H}_{3}$ : leverage berpengaruh terhadap fraud

\section{Hubungan antara Receivable dengan Fraud}

Receivable adalah persentase untuk mengukur pertumbuhan piutang perusahaan atas penjualan tiap tahun. Tingginya piutang dalam penjualan menurut penelitian. Skouses, et al (2009) menunjukan bahwa akun piutang merupakan aset yang memiliki risiko manipulasi lebih tinggi. Maka rawan terjadi kecurangan dalam laporan keuangan.

$\mathrm{H}_{4}$ : Receivable berpengaruh terhadap Fraud

\section{METODE RISET}

Perusahaan Manufaktur Sektor Barang Konsumsi yang terdaftar di Bursa Efek Indonesia sebanyak 39 perusahaan periode 2015 - 2019 merupakan populasi pada penelitian ini. Sampel dalam penelitian ini adalah 17 perusahaan manufaktur sektor barang konsumsi periode 2015 - 2019 yang diduga melakukan fraud. Untuk menentukan apakah perusahaan terindikasi melakukan manipulasi (fraud) atau tidak, peneliti menggunakan model perhitungan Beneish M-Score. Dengan kriteria sebagai berikut:

a. Jika Benesih M-Score lebih besar dari 2.22 mengindikasikan bahwa laporan keuangan telah dimanipulasi.

b. Jika Benesih M-Score lebih kecil dari -2.22 maka perusahaan dikategorikan sebagai perusahaan yang tidak melakukan manipulasi ( non fraud). 


\section{Analisis Statistik Deskriptif}

Statistik deskriptif berfungsi mendeskripsikan objek yang diteliti melalui data sampel atau populasi apa adanya berdasarkan pada nilai minimum, nilai maksimum, mean, dan standar deviasi, dengan tanpa melakukan analisis dan membuat kesimpulan yang berlaku umum dari data tersebut. (Ghozali, 2013).

\section{Analisis Korelasi Suatu Model Regresi (Goodness of Fit)}

Ketepatan fungsi regresi sampel dalam menaksir nilai aktual dapat diukur dari goodness of fit. Secara statitik dapat diukur dari nilai koefisien determinasi, nilai statistik $\mathrm{F}$ dan nilai statistik t. Perhitungan statistik disebut signifikan secara statistik apabila nilai uji statistiknya berada dalam daerah kritis (daerah di mana Ho ditolak). Sebaliknya disebut tidak signifikan bila nilai uji statistiknya berada dalam daerah di mana Ho tidak dapat ditolak. (Ghozali, 2013).

\section{Metode Analisis Regresi Data Panel}

Analisis regresi data panel adalah pengembangan dari analisis data regresi. Terdapat tiga model regresi yang ada yaitu Common Effect Model, Fixed Effect Model, dan Random Effect Model.

\section{Uji Signifikasi Ketepatan Model Regresi}

Untuk menentukan metode mana yang paling sesuai, harus dilakukan tiga buah Uji yaitu, Uji Hausman (Hausman test), Uji Chow (Chow Test), dan Uji Langrange Multiflier (LM Test). Regresi dengan data panel memiliki langkahlangka yaitu: Eksplorasi, Identifikasi, Estimasi, Pengujian Signifikansi, Uji Asumsi dan Goodness of fit model. (Ghozali, 2013).

\section{Pengujian Asumsi Klasik}

Dalam Eviews, uji normalitas dapat dilakukan dengan uji Jerque-Bera (JBtest). Untuk mengambil keputusan, fokus pada Jerque-Bera dan Probability. Dalam Ghozali (2013:165) Uji JB-test adalah uji normalitas untuk sampel besar (asymptotic). Pertama hitung nilai Skewness dan Kurtosis untuk Residual, kemudian lakukan uji JB.

Uji multikolinieritas bertujuan untuk menguji apakah pada model regresi ditemukan adanya korelasi antarvariabel bebas/independen. (Ghozali, 2013: 91). Pada model regresi yang baik seharusnya tidak terjadi korelasi diantara variabel independen.

Uji heteroskedastisitas bertujuan menguji apakah dalam model regresi terjadi ketidaksamaan varians dari residual satu pengamatan ke pengamatan lain. (Ghozali, 2013: 105). Model regresi yang baik adalah Homoskesdastisitas.

\section{Pengujian Hipotesis}

Uji Signifikasi ANOVA (F test) pada dasarnya menunjukkan apakah semua variabel independen atau bebas yang dimasukkan dalam model mempunyai 
pengaruh secara bersama-sama terhadap variabel dependen/ terikat (Ghozali, 2013).

Uji Signifikasi Parsial ( $t$ test) pada dasarnya menunjukkan seberapa jauh pengaruh satu variabel penjelas/independen secara individual dalam menerangkan variasi variabel dependen (Ghozali, 2013). Nilai koefisien determinasi adalah antara nol dan satu. Nilai $\mathrm{R}^{2}$ yang kecil berarti kemampuan variabel-variabel independen dalam menjelaskan variasi variabel dependen sangat terbatas. Nilai yang mendekati satu berarti variabel-variabel independen memberikan hampir semua informasi yang dibutuhkan untuk memprediksi variasi variabel dependen (Ghozali, 2013:83).

\section{ANALISIS DATA DAN PEMBAHASAN}

Setelah melalui hasil uji Chow dan hasil uji Hausman dengan nilai probability masing-masing dibawah 0.05, menunjukan bahwa fixed effect model ditandingkan dengan common effect model dan random effect model tidak dapat terbantahkan untuk dijadikan model terpilih data panel dalam penelitian ini. Berikut adalah FEM model terpilih.

\section{Tabel 2 Fixed Effect Model}

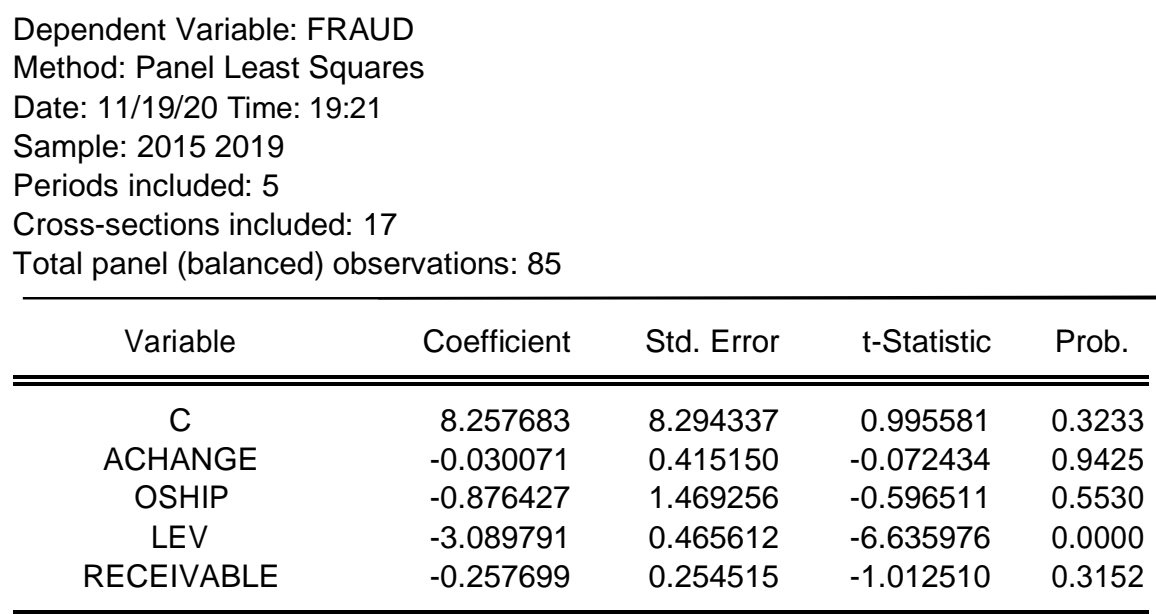

Effects Specification

\begin{tabular}{|c|c|c|c|}
\hline \multicolumn{4}{|c|}{ Cross-section fixed (dummy variables) } \\
\hline R-squared & 0.523575 & Mean dependent var & -0.400586 \\
\hline Adjusted R-squared & 0.364767 & S.D. dependent var & 0.307533 \\
\hline S.E. of regression & 0.245108 & Akaike info criterion & 0.243896 \\
\hline Sum squared resid & 3.784915 & Schwarz criterion & 0.876112 \\
\hline Log likelihood & 11.63440 & Hannan-Quinn criter. & 0.498191 \\
\hline F-statistic & 3.296905 & Durbin-Watson stat & 2.574347 \\
\hline Prob(F-statistic) & 0.000132 & & \\
\hline
\end{tabular}

* Corresponding author's e-mail:dosen02425@unpam.ac.id http://openjournal.unpam.ac.id/index.php/JABI 
Sumber: EViews versi 9.0 for windows, 2020

Berdasar pada tabel 2, diperoleh nilai $F$ hitung sebesar 3.297 dengan probabilitas sebesar 0.0001. Oleh karena probabilitas jauh lebih kecil dari 0.05, maka dapat disimpulkan bahwa koefisien regresi Achange, Oship, Lev, Receivable secara simultan berpengaruh positif terhadap Fraud.

Berdasarkan Tabel 2 nilai signifikansi Achange sebesar $0.9425>0.05$ dengan nilai $t_{\text {hitung }}$ sebesar $-0.0724<\mathrm{t}_{\text {tabel }}$ sebesar 1.9905 dan nilai koefisien sebesar 0.030071 berdasarkan hasil di atas maka $\mathrm{H} 1$ ditolak dan $\mathrm{H} 0$ diterima, yang berarti achange tidak berpengaruh terhadap fraud secara parsial, dengan demikian H1 tidak terbukti mendeteksi fraud. nilai koefisien regresi achange adalah -0.0301, artinya jika tingkat perubahan aset berubah satu satuan, maka nilai fraud juga akan berubah sebesar - 0.0301 dengan asumsi variabel independen yang lainnya adalah konstan/tidak berubah. Tanda negatif koefisien tersebut menunjukan hubungan yang berlawanan arah antara variabel perubahan aset dan fraud, ini berarti jika persentase perubahan aset semakin meningkat, maka nilai fraud akan turun sebesar 0.0301."

Nilai signifikansi Oship sebesar $0.5530>0.05$ dengan nilai thitung sebesar 0.5965 < tabel sebesar 1.9905 berdasarkan hasil di atas maka $\mathrm{H}_{1}$ ditolak dan $\mathrm{H}_{0}$ diterima, yang berarti Oship tidak berpengaruh terhadap Fraud secara parsial. Dengan demikian $\mathrm{H}_{2}$ tidak terbukti mendeteksi Fraud. Nilai koefisien regresi Oship adalah -0.8764, artinya jika tingkat kepemilikan saham berubah satu satuan, maka nilai Fraud juga akan berubah sebesar -0.8764 dengan asumsi variabel independen yang lainnya adalah konstan/tidak berubah. Tanda negatif koefisien tersebut menunjukan hubungan yang berlawanan arah antara variabel kepemilikan saham orang dalam dan Fraud, ini berarti jika persentase kepemilikan saham orang dalam semakin meningkat, maka nilai fraud akan turun sebesar 0.8764 .

Nilai signifikansi Leverage sebesar $0.000<0.05$ dengan nilai thitung sebesar $6.6359>\mathrm{t}$ tabel sebesar 1.9905 berdasarkan hasil di atas maka $\mathrm{H}_{0}$ ditolak dan $\mathrm{H}_{1}$ diterima, yang berarti Leverage berpengaruh signifikan terhadap Fraud secara parsial. Dengan demikian $\mathrm{H}_{3}$ terbukti mendeteksi Fraud. "Nilai koefisien regresi Leverage atau tekanan hutang pihak luar adalah -3.0898 , artinya jika tingkat tekanan hutang pihak luar berubah satu satuan, maka nilai fraud juga akan berubah sebesar -3.0898 dengan asumsi variabel independen yang lainnya adalah konstan/tidak berubah. Tanda negatif koefisien tersebut menunjukan hubungan yang berlawanan arah antara variabel Leverage dan Fraud, ini berarti jika persentase Leverage semakin meningkat, maka nilai Fraud akan turun sebesar 3.0898 .

Nilai signifikansi Receivable sebesar $0.3152>0.05$ dengan nilai thitung sebesar 1.0125 < tabel sebesar 1.9905 berdasarkan hasil di atas maka $\mathrm{H}_{1}$ ditolak dan $\mathrm{H}_{0}$ diterima, yang berarti Receivable tidak berpengaruh terhadap Fraud secara parsial. Dengan demikian $\mathrm{H}_{4}$ tidak terbukti mendeteksi Fraud. Nilai koefisien regresi Receivable adalah -0.257 , artinya jika tingkat Receivable berubah satu satuan, maka nilai Fraud juga akan berubah sebesar -0.257 dengan asumsi variabel

* Corresponding author's e-mail:dosen02425@unpam.ac.id 
independen yang lainnya adalah konstan/tidak berubah. Tanda negatif koefisien tersebut menunjukan hubungan yang berlawanan arah antara variabel Receivable dan Fraud, ini berarti jika persentase Receivable semakin meningkat, maka nilai Fraud akan turun sebesar 0.257 .

Pada tabel 2 nilai $F$ hitung sebesar 3.297 dengan probabilitas sebesar 0.0001 . Oleh karena probabilitas jauh lebih kecil dari 0.05, maka dapat disimpulkan bahwa koefisien regresi Achange, Oship, Lev, Receivable tidak sama dengan nol atau dengan kata lain $\mathrm{H}_{1}$ diterima dan menolak $\mathrm{H}_{0}$. Kesimpulan hasil outputnya adalah kelima variabel independen secara simultan berpengaruh positif terhadap fraud. Dengan demikian $\mathrm{H}_{5}$ dalam penelitian ini terbukti.

Model persamaan regresi yang dihasilkan dari tabel 1 adalah:

Fraud $=8.2577-0.030$ IAchange -0.8764 Oship -3.0898 Lev-0.2577Receivable $+\mathrm{e}$

\section{Pengaruh Achange Terhadap Fraud}

Achange tidak berpengaruh terhadap Fraud. Hasil penelitian ini konsisten dengan penelitian yang dilakukan Soraya (2013), Andri (2014), Norbarani (2012) dan Lou and Wang (2009) dan bertentangan dengan penelitian yang dilakukan Skousen et,al (2008) dan Elandi (2016). Tanda negatif pada koefisien di Tabel 1 sebesar sebesar -0.030071 menunjukan hubungan yang berlawanan arah antara perubahan asset yang diproksikan dengan Achange dan kecurangan (fraud), Andri (2014) dalam penelitiannya mengungkapkan ketika perusahaan mengalami peningkatan perubahan aset yang tinggi, tentu perusahaan akan mendapat perhatian masyarakat karena asset yang tinggi dapat meyakinkan pihak investor, Bank, Pemerintah, kreditur dan supplier untuk memberikan pendanaan lebih dengan maksud tingkat pengembalian yang besar. Pengembalian yang besar menjadi tanggungjawab perusahaan dalam menyelesaikan kewajibannya. Disisi inilah perusahaan lebih cenderung berhati-hati melaporkan laporan keuangan perusahaannya dan lebih cenderung melaporkan laporan keuangan dengan kondisi kekayaan yang sebenarnya, sebab itulah kecurangan menurun. (Lou and Wang, 2009).

\section{Pengaruh Oship terhadap Fraud}

Oship tidak berpengaruh terhadap Fraud. Hasil penelitian ini sejalan dengan Widiarti (2015), Iqbal dan Murtanto (2016) dan Wulandari (2016) dan bertentangan dengan hasil penelitian yang dilakukan dengan Soraya (2013). Widiarti (2015) dan Wulandari (2016) mengungkapkan pihak manajemen yang mempunyai persentase kepemilikan saham dalam jumlah kecil atau pun besar akan tetap melakukan manajemen laba. Hal ini diduga terjadi akibat pengaruh pihak investor yang membuat pihak manajemen merasa terikat untuk memenuhi target pencapaian laba, sehingga mereka cenderung akan tetap terlibat dalam tindakan manajemen laba agar tercapainya target perusahaan yang telah ditetapkan. Nilai negatif koefisien regresi Oship menunjukan hubungan yang berlawanan arah antara kepemilikan saham orang dalam dan Fraud, ini berarti jika persentase kepemilikan saham orang dalam semakin meningkat, maka nilai Fraud akan turun sebesar 0.8764. Widiarti (2015) menyebutkan, pada praktiknya 
dibeberapa perusahaan kepemilikan saham orang dalam disertakan untuk menjaga keputusan atau kebijakan perusahaan berjalan sebagaimana mestinya dari tekanan investor pihak luar, sehingga peningkatan saham orang dalam dapat menurunkan tingkat kecurangan (fraud) yang terjadi di perusahaan.

\section{Pengaruh Leverage terhadap Fraud}

Leverage berpengaruh terhadap Fraud. Hasil penelitian ini sejalan dengan penelitian yang dilakukan oleh Rachmania (2016) dan Listiyawati (2016) dan menetang hasil penelitian yang dilakukan oleh Elandi (2016), Iqbal dan Muranto (2016), dan Mafiana dkk (2016). Person (1999) dalam Tifani (2015) menyatakan bahwa leverage (LEV) yang lebih besar dapat dikaitkan dengan kemungkinan yang lebih besar untuk melakukan pelanggaran terhadap perjanjian kredit dan kemampuan yang lebih rendah untuk memperoleh tambahan modal melalui pinjaman. Hasil ini juga mendukung pendapat Skousen et al. (2009), manajemen perusahaan akan merasa tertekan dengan utang yang semakin besar, karena risiko kreditnya juga akan tinggi, sehingga memungkinkan terjadinya kecurangan.

\section{Pengaruh Receivable terhadap Fraud}

Receivable tidak berpengaruh terhadap Fraud. Penelitian ini konsisten dengan penelitian yang dilakukan oleh Saiful (2017), Iqbal dan Murtanto (2016) dan Elandi (2016) namun hasil penelitian ini tidak sejalan dengan penelitian yang dilakukan oleh Sukirman dan Maylia (2013). Saiful (2017) mengemukakan bahwa ditolaknya hipotesis ini karena nilai rata-rata perubahan piutang perusahaan dari tahun sebelumnya tidak berpengaruh terhadap perputaran kas perusahaan. Banyaknya piutang usaha yang dimiliki perusahaan tidak mengurangi jumlah kas yang dapat digunakan perusahaan untuk kegiatan operasionalnya sehingga rasio perubahan dalam piutang usaha tidak memicu manajemen untuk melakukan kecurangan laporan keuangan.

\section{Pengaruh Achange, Oship, Leverage dan Receivable terhadap Fraud}

Dapat disimpulkan bahwa keempat variabel independen secara simultan berpengaruh positif terhadap Fraud. Tiffani (2015) menjelaskan, pada dasarnya financial stability (Achange), personal financial need (Oship), external pressure (Leverage), dan nature of industry (Receivable) merupakan gagasan yang dikemukakan oleh Cressey pada tahun 1953 dalam penelitiannya melalui beberapa serangkaian wawancara dengan 113 (seratur tiga belas) narapidana yang telah dihukum karena melakukan penggelapan uang perusahaan. Kemudian Cressey menyimpulkan banyak factor yang menyebabkan terjadinya kecurangan penggelapan uang, diantaranya variabel-variabel di atas.

Gagasan ini dikenal dengan fraud triangle. Gagasan triangle fraud sudah diakui oleh beberapa lembaga akuntansi dan audit di Indonesia maupun dunia dan dikeluarkan dalam bentuk standar diantarnya SAS No. 99, ISA No. 240, IAPI No 70 dan TSAS No. 43 Achange, Oship, Leverage Dan Receivable secara bersamasama dapat digunakan untuk mendeteksi Fraud. 


\section{KESIMPULAN DAN SARAN}

Hasil penelitian menunjukkan bahwa hanya leverage yang berpengaruh signifikan negatif terhadap fraud secara parsial, achange, oship dan receivable tidak berpengaruh signifikan terhadap fraud, tetapi achange, oship, leverage dan receivable secara simultan berpengaruh signifikan positif terhadap fraud. Dengan demikian untuk mendeteksi terjadinya fraud disuatu perusahaan seyogyanya tidak hanya memperhatikan satu persatu variabel dalam pendeteksian kecurangan laporan keuangan (Fraud) namun juga perlu diuji dengan variabel lain. Karena akun/ rekening pada laporan keuangan saling memiliki keterkaitan yang erat, dan biasanya para pelaku fraud yang melakukan kecurangan adalah orang yang ahli ataupun orang yang sangat paham dalam membuat laporan keuangan, sehingga untuk mendeteksinya harus dilakukan analisa yang mendalam dan komprehensif. Sekaligus diperlukan pengujian secara observasi dan wawancara demi meyakinkan dugaan kecurangan laporan keuangan.

Sara untuk penelitian selanjutnya untuk dapat menambah tahun penelitian dan menambah sektor selain perusahaan manufaktur sektor barang konsumsi untuk dapat menghasilkan kesimpulan yang lebih komprehensif dan lebih baik lagi. Penelitian selanjutnya juga disarankan agar menambah proksi lain dari variable-variabel triangle fraud yang berbeda, seperti Ineffective monitoring, financial target dan organization structure.

\section{DAFTAR PUSTAKA}

AICPA, SAS No. 99. (2002). Consideration of FRAUD in a Financial Statement Audit, AICPA. NewYork.

Andriyanto R, Effriyanti, Hidayat A. (2018). The Effect of Spiritual Intelligence (SQ) and Personality Types on Auditor's Ability to Detect FRAUD. Jurnal Akuntansi Berkelanjutan Indonesia (JABI), Vol.1 No.3 Sept 2018. P-ISSN: 2615-7896

Beneish, Messod D. (1999). The Detection of Earnings Manipulation. Financial Analyst Journal 55(5): 24-36

Cressey, D. (1953). Other people's money, dalam: The Internal Auditor as Fraud buster, Hillison, William. Et. Al. 1999. Managerial Auditing Journal, MCB University Press, Vol. 14 (7):351-362.

Elandi, Kharisma. (2016). Analisis Fraud Triangle Untuk Mendeteksi Kecurangan Laporan Keuangan Pada Perusahaan Go Public Non Perbankan dan Jasa Keuangan Periode 2012-2015. Jurnal Akuntansi IBS

Ghozali, I. (2013). Aplikasi Analisis Multivariate Dan Ekonometrika Dengan Program EViews 8. Semarang: BP Universitas Diponegoro

* Corresponding author's e-mail:dosen02425@unpam.ac.id

http://openjournal.unpam.ac.id/index.php/JABI 
International Federation of Accountants (IFAC). (2016). International Standard on Auditing (ISA) No.240. Diakses kembali dari Web site: www.ifac.org pada 6 Februari 2021.

Institut Akuntan Publik Indonesia (IAPI). (2016). Pernyataan Standar Auditing (PSA) No. 70 (SA Seksi 316 paragraf 4,). Pertimbangan atas Kecurangan dalam Audit Laporan Keuangan, Standar Profesional Akuntan Publik, Jakarta.

Iqbal, Muhamad dan Murtanto. (2016).Analisa Pengaruh Faktor-Faktor FRAUD Triangle Terhadap Kecurangan Laporan Keuangan Pada Perusahaan Property dan Real Estate yang Terdaftar di Bursa Efek Indonesia. Jurnal Seminar Nasional Cendekiawan 2016 ISSN (E): 2540-7589 ISSN (P): 2460-8696.

Junita, Nuur. (2016). Deteksi Kecurangan Laporan Keuangan Perbankan Syariah Dalam Perspektif Fraud Triangle Theory. Jurnal FEBI Universitas Islam Negeri Sunan Kalijaga Yogyakarta.

Lou, Y. and M. Wang. (2009). Fraud Risk Factor of the Fraud Triangle Assesing the Likehood of Fraudulent Financial Reporting. Journal of Business \& Economic Research, Vol. 7 (2): 61-78.

Mafiana, dkk. (2016). Pendeteksian Kecurangan Laporan Keuangan Menggunakan FRAUD Diamond. Jurnal Bisnis dan Ekonomi (JBE), Maret 2016, Hal. 72 - 89 Vol. 23, No. 1 ISSN: 1412-3126.

Magfiroh, Nur. (2014). Analisis Pengaruh ACHANGE, OSHIP, LEVERAGE, dan Ineffective Monitoring pada Financial Statement FRAUD dalam Perspektif FRAUD. Jurnal Ekonomi dan Bisnis.Volume 16. Nomor 01. Maret 2015

Rachmania, Annisa. (2017). Analisis Pengaruh Fraud Triangle Terhadap Kecurangan Laporan Keuangan Pada Perusahaan Makanan dan Minuman Yang Terdaftar di Bursa Efek Indonesia Periode 2013-2015. JOM Vol. 2 No. 2 (2017). FE Universitas Pakuan. Bogor.

Ramadhan AP, dan Ruhiyat E. (2020). Kecurangan Akademik: FRAUD Diamond, Perilaku Tidak Jujur dan Persepsi Mahasiswa. Jurnal Akuntansi Berkelanjutan Indonesia (JABI), Vol.3 No.1 Jan 2020. P-ISSN: 2615-7896

Saiful, Muhammad dan Achmad Uzaimi. (2017). Deteksi Financial Statement Fraud Dengan Analisis Fraud Triangle Pada Perusahaan Aneka Industri Yang Terdaftar di Bursa Efek Indonesia 2012-2015. Jurnal Repositori. FE Universitas Maritim Raja Ali Haji.

Skousen, C. J., K. R. Smith, dan C. J. Wright. (2008). Detecting and Predecting Financial Statement Fraud: The Effectiveness of The Fraud Triangle and SAS No. 99. Corporate Governance and Firm Performance Advances in Financial Economis, Vol. 13: 1-39. 
Soraya, Dara Inda. (2013). Pendeteksian Financial Statement Fraud Berdasarkan Perspektif Fraud Triangle Pada Perusahaan Manufaktur Di Bursa Efek Periode 2010-2012. Jurnal FEB Universitas Lampung.

Sukirman dan Maylia. (2012). Model Deteksi Kecurangan Berbasis FRAUD Triangle.Jurnal Akuntansi dan Auditing, Vol. 9 (2): 199-225.

Tiffani, Laila dan Marfuah. (2015). Deteksi Financial Statement Fraud dengan Analisis Fraud Triangle pada Perusahaan Manufaktur yang Terdaftar di Bursa Efek Indonesia. Simposium Nasional Akuntansi Vol. 18, 18:049

Tuanakotta, Theodorus M. (2013). Audit Berbasis ISA. Jakarta: Salemba Empat

.2007. Akuntansi Forensik dan AuditInvestigasi. Jakarta: Lembaga Penerbit Fakultas Ekonomi Universitas Indonesia.

Turner, Jerry L., Theodore J. Mock, and Rajendra P. Srivastava. (2003). An Analysis of the Fraud Triangle. The University of Memphis, University of Southen California, University of Kansas, (Online), (http://aaahq.org, diakses 3 Agustus 2017, pkl 09.23 WIB).

Widiarti. (2015). Pengaruh Fraud Triangle Terhadap Deteksi Kecurangan Laporan Keuangan Pada Perusahaan Manufaktur Yang Terdaftar di Bursa Efek Indonesia (BEI). Jurnal FE Universitas Tamansiswa Palembang. 